\title{
Psychological aspects of von Recklinghausen neurofibromatosis (NF1)
}

Svend Erik Mouridsen, Sven Asger Sørensen

\begin{abstract}
Neurofibromatosis is a devasting autosomal dominant disease which is extremely variable in its symptomatology, intensity, and progression. There have been numerous reports published about the physical aspects of neurofibromatosis, while psychological issues have been given little attention so far. The present article presents a review of the current knowledge concerning psychological aspects of neurofibromatosis. Information is provided relating to physical appearance, intellectual impairment, neuropsychological findings, learning disability, and psychiatric disorders.
\end{abstract}

( $($ Med Genet 1995;32:921-924)

Von Recklinghausen's neurofibromatosis (NF1) is a chronic progressive genetic disease with an autosomal dominant pattern of inheritance. The disease affects about 1 in 3000 subjects $^{1}$ and is characterised mainly by café au lait spots, neurofibromas, and optic glioma. Internationally accepted diagnostic criteria for NF1 have been available since $1988 .^{2} \mathrm{NF} 1$ has been mapped to the proximal long arm of chromosome $17 .^{34}$ The gene locus has been cloned ${ }^{5}$ and prenatal diagnosis is now possible. ${ }^{6}$ About one half of the affected persons have inherited the gene from a parent, and one half have developed NF1 as the result of a spontaneous mutation.

The phenotypic expression of NF1 is quite variable, with some patients meeting only the minimum criteria necessary for diagnosis, whereas others are severely affected by cutaneous or other manifestations of this condition. The NF1 gene has the potential for multiple organ system involvement, and there is often an increase in the number of neurofibromas during puberty, at the time when young people are most concerned about their body image. Prognosis is difficult to predict, but life threatening complications may occur and the survival rate is reduced. ${ }^{7}$ The unpredictable nature of NF1 makes it particularly difficult for the patient to cope with. Even a patient with minimal manifestations of the illness may live in constant fear and uncertainty.
The cognitive abilities and behavioural aspects associated with specific genetic syndromes are of great importance to geneticists and other advisers, enabling them to offer more effective information and supportive counselling to families with a genetic disease. The extreme variability in the phenotypic expression of the NF1 gene even within families makes it particularly difficult for patients to comprehend the variety of problems associated with NF1 and studies have noted that patients often know little about clinical and genetic aspects. ${ }^{18} \mathrm{An}$ other reason for studying psychological aspects of genetic disorders is that although cognitive abilities are most often inherited in a multifactorial way, ${ }^{9}$ single gene disorders may have a selective impact on brain development, resulting in specific cognitive deficits. ${ }^{10}$ Therefore, the study of genetic disorders may shed light on this development and provide further insight into the heritability of human cognitive functioning.

There are numerous reports about physical aspects of neurofibromatosis. However, information on psychological aspects is scanty and the reported findings are often based on highly selected groups of patients sometimes not assessed in a systematic manner with standardised measures. In the following review particular attention is given to physical appearance and psychological development, intellectual impairment, neuropsychological findings, learning disabilities, and psychiatric disorders.

\section{Physical appearance}

A person's physical appearance, along with his sexual identity, is the personal characteristic most obvious and accessible to others in social interaction. Generally, empirical research unequivocally documents that greater physical attractiveness is favourable for a person, and lesser physical attractiveness is unfavourable. For example, persons of greater physical attractiveness are perceived to be more socially skilled, live better lives, and have more successful marriages and occupations. ${ }^{11}$ Society is often prejudiced against those with an atypical facial appearance, and a person with a facial disfigurement may experience severe social handicap. ${ }^{12}$ 
Only a minimum number of patients display the severe disfigurement of NF1. However, plexiform neurofibromas, short stature, macrocephaly, and scoliosis ${ }^{1}$ are well known signs and complications of the disease which affect physical appearance. Like others who are mildly disfigured, the neurofibromatosis patient often harbours an exceedingly distorted perception of self, leading to social isolation. ${ }^{1314}$ Samuelsson and Samuelsson ${ }^{15}$ noted that many patients complained of short stature, and some of the men said that they had been teased because they were smallest in their class during school years. Many women said that they had ceased wearing low necked or short sleeved dresses and would no longer wear a bikini. In addition many patients found it very distasteful when they saw other people staring at the nodules on their bodies. ${ }^{16}$ Benjamin $e t a l^{8}$ also observed that many people had difficulty in accepting the cosmetically disfiguring aspects of NF1. These included enlarged head size, facial plexiform neurofibromas, and pseudarthrosis. However, there was no correlation between individual perception and medical classification of severity, with the majority of patients perceiving themselves more severely affected than they were. Many patients described restrictions in social contact and changes in life style to try to hide peripheral neurofibromas. They also reported concealing the lumps in order to avoid explaining the condition to other people, and young adults felt that cosmetic features reduced their confidence in their ability to form relationships.

\section{Intellectual impairment}

It is difficult to determine the true incidence of intellectual impairment, learning disability, and behavioural disorders associated with NF1 There is a considerable range in different studies and conclusions are often based on rather crude measures such as number of years of schooling, class placement, personal history, or parental reports, rather than more objective measures like standardised intelligence test scores or behavioural scales. In addition there may be a substantial bias in data only obtained from hospital records or disease specific clinics. Thus it is important to emphasise that in the reporting of frequency figures, the actual occurrence of more serious manifestations may be overstated because of failure to ascertain mildly affected cases in which a medical opinion had not been sought.

The incidence of intellectual impairment has varied a great deal depending on selection ${ }^{17}$ and what IQ criteria have been used. It is, however, generally accepted that severe mental retardation is not a typical manifestation of NF1; rather there appears to be a shift in the distribution of IQ scores towards generally lower ranges of functioning. ${ }^{18}$ Among 203 formally tested children, $17(18.4 \%)$ had an IQ of less than 70 compared with about $3 \%$ of the general population. ${ }^{19}$ Others have reported figures between 6 and $21 \%$. $^{1820-22}$ Others have used IQ scores at or below 85 as the primary criterion for designating mental retardation and have reported findings between $3 \cdot 2$ and $45 \% .^{123-27}$ The underlying neuropathology of the intellectual difficulties has not been established. Recently, Ferner et $a l^{28}$ were unable to find any correlation between the presence of intensity lesions on MRI scans and the occurrence of mental retardation in children or adults with NF1.

\section{Neuropsychological aspects}

Following the application of comprehensive neuropsychological test batteries, a common finding has been that subjects with NF1 performed better in verbal than non-verbal tests. ${ }^{1821-232629-32}$ These observations can indicate better auditory processing skills than visuospatial processing abilities. It seems that many NF1 patients have a specific neuropsychological profile. However, the observed cognitive profile is hardly a pattern unique for NF1. Other populations, for example, girls with Turner's syndrome, have a well documented presence of deficits in the spatial aspects of cognitive processing. ${ }^{33}$ However, even in such cases, the relationship between the chromosomal anomaly and deficient cognitive skills remains controversial and ill defined. The factors underlying this pattern of deficit are unclear but are potentially related to the genetic factors underlying the syndrome. The described neuropsychological pattern is often associated with a right hemisphere dysfunction. ${ }^{3435}$

\section{Learning disabilities}

Academic difficulties and learning disabilities appear to be a common manifestation of NF1. However, the frequency of learning disabilities and related problems in children with NF1 is difficult to ascertain, as the criteria for learning disability remain somewhat problematical and vary among investigators. In addition proper control populations are not always available. In the population based study in Wales of Huson et al, ${ }^{1} 29 \cdot 8 \%$ of all subjects required remedial class education or had a specific learning difficulty. Their findings are probably the most accurate because this study came as close as it could to unselected ascertainment. Other studies have cited figures around 24 to $45 \%$. ${ }^{1819212224262732}$ In the study of Benjamin $e t a l^{8} 77 \%$ of the parents involved said that NF1 had caused problems for their child at school. These included learning difficulties, difficulties in forming friendships, and behavioural problems. Thirty-two percent of the parents reported the involvement of an educational psychologist.

More recent studies have yielded an improved description of the types of learning disabilities found in NF1..$^{21^{2329-31}}$ When analysing the neuropsychological data of these patients in an attempt to identify cognitive subtypes of learning disabilities, the authors found an interesting pattern in comparison to children evaluated for learning disability without NF1. Children with NF1 had a significantly lower full scale IQ, although well within the 
normal range. However, a visual-perceptual disability was noted significantly more often than in control subjects. This pattern of cognitive strength and weakness was remarkably dissimilar from that seen in non-NF1 children with learning disabilities. ${ }^{2329}$ in whom language disabilities generally predominate. These data have so far been accepted as an important neuropsychological disability in some learning disabled children with $\mathrm{NF} 1$, also indicating that frank mental retardation is not a common cause of learning disorders in NF1. The neuropathology of the learning problems has so far not been established. Recent studies ${ }^{3637}$ using MR brain imaging have not been able to find a correlation between the presence of increased intensity lesions on MR scans and learning difficulties in the children studied. However, the exploration of the strengths and weaknesses in academic abilities, especially in those with average intelligence, can assist educators in further delineation of the syndrome and may provide suggestions for educational remediation and for the development of programmes to enhance adaptive life skills.

\section{Psychiatric disorders}

There is some question as to whether psychiatric and developmental disorders are truly over-represented in patients with NF1 particularly when patients with neurofibromatosis are compared to those with other chronic neurological disorders. ${ }^{19}$ Since NF1 is a common disease there is also a substantial risk of its fortuitous association with other conditions. In the study of Samuelsson and Axelson, ${ }^{38}$ $18 \%$ of the children were described as having behavioural disorders, although these were not further delineated. In Dunn's series ${ }^{24}$ of 55 children seen prospectively, one child had symptoms of autism, one was withdrawn and depressed, and nine had a possible attention deficit disorder. Attention deficit disorder has also been pointed out in several other reports, ${ }^{181921-2326}$ suggesting that as many as nearly $50 \%$ may be inflicted. ${ }^{23}$ Additionally, Eliason $^{29}$ also called attention to social imperception. The misinterpretation of nonverbal communication such as gestures and facial expression may lead them to behave in an inappropriate fashion. Attention deficit disorder and social imperception in addition to the described pattern of neuropsychological impairment are all major behavioural symptoms often associated with right hemisphere dysfunction. ${ }^{3435}$ Some of these patients also meet the criteria for autistic disorder and the boundary between autistic disorder and the right hemisphere deficit syndrome is not clear. ${ }^{39}$

Concomitant occurrence of NF1 and autistic disorder has also been described in several other reports. ${ }^{40-45}$ However, whether autism is associated with NF1 in a stronger than chance fashion has so far not been systematically assessed in a representative sample.

Samuelsson et al, ${ }^{151625}$ who have been the only investigators systematically to assess psychiatric and social aspects of NF1 in a carefully defined population, determined that 23 (33\%) of 69 adult patients with NF1 had mental illness of various types, but a comparison group was not studied in the same fashion to provide a context for interpreting the NF1 patient data. The 23 mentally ill patients did not show any uniform clinical psychiatric syndrome. The most commonly occurring diagnoses were depressive syndrome, anxiety state with vegetative dysfunction, and organic brain syndrome. In addition, the data also indicated an excess of occupational disability, unemployment, or employment in a position characterised as not requiring special skills. Only four of 69 patients studied were gainfully employed in positions requiring three to four years of vocational training.

In conclusion, in addition to medical complications, people with NF1 are vulnerable to problems with intellectual, academic, and social skills and it will often be necessary to ensure that they are able to make optimal use of academic and vocational programmes. Further, the knowledge being obtained from studies of children and adults with NF1 can be applied meaningfully in genetic counselling and be used to enhance our understanding of cognitive and behavioural development in unaffected subjects. Future detailed, comprehensive studies of unselected populations are required using standardised assessments of cognitive disabilities and behavioural attributes to delineate the issues raised in this review further.

This work was supported by a grant from Mrs C Hermansen's Mindelegat.

1 Huson SM, Harper PS, Compston DAS. Von Recklinghausen neurofibromatosis. A clinical and population study in South-East Wales. Brain 1988;111:1355-81.

2 National Institutes of Health Consensus Development Conference. Neurofibromatosis conference statement. Arch Neurol 1988;45:575-8.

3 Barker D, Wright E, Nguyen K, et al. Gene for von Recklinghausen neurofibromatosis is in the pericentromeric region of chromosome 17. Science 1987;236:1100-2.

4 Seizinger BR, Rouleau GA, Ozelius LJ, et al. Genetic linkage of von Recklinghausen neurofibromatosis to the nerve of von Recklinghausen neurofibromatosis to the
growth factor receptor gene. Cell 1987;49:589-94.

5 Wallace MR, Marchuk DA, Andersen LB, et al. Type 1 neurofibromatosis gene: identification of a large transcript neurofibromatosis gene: identification of a large transcript
disrupted in three NF1 patients. Science 1990;249:181-6.

6 Upadhyaya M, Fryer A, MacMillan J, et al. Prenatal diagnosis and presymptomatic detection of neurofibromatosis type 1. F Med Genet 1992;29:180-3.

7 Sørensen SA, Mulvihill JJ, Nielsen A. On the natural history of von Recklinghausen neurofibromatosis. Ann NY Acad Sci 1986;486:30-7.

8 Benjamin CM, Colley A, Donnai D, et al. Neurofibromatosis type 1 (NF1): knowledge, experience, and reproductive decisions of affected patients and families. $\mathcal{F}$ Med Genet 1993;30:567-74

9 DeFries JC, Vandenberg SG, McClearn GE. Genetics of specific cognitive abilities. Annu Rev Genet 1976;10:179207.

10 Chudley AE, de von Flindt R, Hagerman RJ. Cognitive variability in the fragile $\mathrm{x}$ syndrome. Am $\mathcal{f}$ Med Genet 1987;28:13-15.

11 Dion K, Berscheid E, Walster E. What is beautiful is good. f Pers Soc Psychol 1972;24:285-90.

12 Bull R. Society's reaction to facial disfigurement. Br Psychol Soc Newslet 1990;7:10-2.

13 Roback HB, Kirshner H, Roback E. Physical self-concept changes in a mildly, facially disfigured neurofibromatosis changes in a mildly, facially disfigured neurofibromatosis patient following communication

14 Hett DA, Mather S, Dewar, EP. Von Recklinghausen's disease of the nerves: a modern day social response. $\mathcal{F}$ Roy Nav Med Serv 1989;75:139-41.

15 Samuelsson B, Samuelsson S. Neurofibromatosis in Gothenburg, Sweden. I. Background, study design and epidemiology. Neurofibromatosis 1989;2:6-22.

16 Samuelsson B, Riccardi VM. Neurofibromatosis in Gothenburg, Sweden. III. Psychiatric and social aspects. Neur fibromatosis 1989;2:84-106.

17 Garty BZ, Laor A, Danon YL. Neurofibromatosis type 1 in Israel: survey of young adults. $\mathcal{f}$ Med Genet 1994;31: 853-7.

18 Ferner RE. Intellect in neurofibromatosis 1. In: Huson SM, 
Hughes RAC, eds. The neurofibromatoses. A pathogenetic and clinical overview. London: Chapman and Hall, 1994: 233-53.

19 Riccardi VM. Neurofibromatosis: phenotype, natural history, and pathogenesis. 2nd ed. Baltimore: Johns Hopkins University Press, 1992

20 Samongo-Sprouse CA, Rosenbaum K, Rodnan L, et al. The incidence of developmental disabilities in toddlers with von Recklinghausen neurofibromatosis (NF-1). Am f Med Genet 1988;43:A68.

21 Legius E, Deschemeemaeker MJ, Spaepen A, et al. Neurofibromatosis type 1 in childhood: a study of the neuropsychological profile in 45 children. Genet Counsel 1994. 5:51-60.

22 Moore BD, Ater JL, Needle MN, et al. Neuropsychological profile of children with neurofibromatosis, brain tumor, or both. F Child Neurol 1994;9:368-77.

23 Eliason MJ. Neurofibromatosis: implications for learning and behavior. Dev Behav Pediatr 1986;7:175-9.

24 Dunn DW. Neurofibromatosis in childhood. Curr Probl Pediatr 1987; 17:451-97.

25 Samuelsson B, Riccardi VM. Neurofibromatosis in Gothenburg, Sweden. II. Intellectual compromise. Neuro-

26 Wadsby $M$, Lindehammar H, Eeg-Olofsson O. Neurofibromatosis in childhood: neuropsychological aspects. Neurofibromatosis 1989;2:251-60

27 North K. Neurofibromatosis type 1: review of the first 200 patients in an Australian clinic. F Child Neurol 1993;8 395-402

28 Ferner RE, Chaudhuri R, Bingham J, et al. MRI in neurofibromatosis 1 . The nature and evolution of increased intensity T2 weighted lesions and their relationship to intellectual impairment. If Neurol Neurosurg Psychiatry 1993;56:492-5.

29 Eliason MJ. Neuropsychological patterns: neurofibromatosis compared to developmental learning disorders. Neurofibromatosis 1988;1:17-25.

30 Varnhagen CK, Lewin S, Das JP, et al. Neurofibromatosis and psychological processes. Dev Behav Pediatr 1988:9: 257-65.

31 Eldridge R, Denckla MB, Bien E, et al. Neurofibromatosis type 1 (Recklinghausen's disease). Neurologic and cognitive assessment with siblings controls. Am $\mathcal{F}$ Dis Child 1989;143:833-7.

32 Stine SB, Adams WV. Learning problems in neurofibromatosis patients. Clin Orthop 1989;245:43-8.

33 Walzer S. X chromosome abnormalities and cognitive development: implications for understanding normal human development. $尹$ Child Psychol Psychiatry 1985;28:177-84.

34 Heilman KM, Bowers D, Valenstein E, et al. The right hemisphere: neuropsychological functions. If Neurosurg 1986;64:693-704.

35 Voeller KKS. Right-hemisphere deficit syndrome in children. Am f Psychiatry 1986;143:1004-9.

36 Duffner PK, Cohen ME, Seidel FG, et al. The significance of MRI abnormalities in children with neurofibromatosis. Neurology 1989;39:373-8.

37 Dunn DW, Roos KL. Magnetic resonance imaging evaluation of learning difficulties in neurofibromatosis. Neuroation of learning difficultie
fibromatosis $1989 ; 2: 1-5$.

38 Samuelsson B, Axelsson R. Neurofibromatosis. A clinical and genetic study of 96 cases in Gothenburg, Sweden. Acta Dermatol Venerol Suppl (Stockh) 1981;95:67-71.

39 Voeller KKS. Clinical neurologic aspects of the right-hemisphere deficit syndrome. f Child Neurol 1995;10(suppl): S16-S22.

40 Gillberg C, Forsell C. Childhood psychosis and neurofibromatosis-more than a coincidence? $\mathcal{F}$ Autism Dev Disord 1984;14:1-8.

41 Gaffney GR, Tsai LY. Magnetic resonance imaging of high level autism. F Autism Dev Discord 1987;17:433-8.

42 Szatmari P, Bremmer R, Nagy J. Asperger's syndrome: A review of clinical features. Can $\mathcal{F}$ Psychiatry 1989;34: 554-60.

43 Steffenburg S. Neuropsychiatric assessment of children with autism: a population based study. Dev Med Child Neurol 1991;33:495-511.

44 Tuchman RF, Rapin I, Shinnar S. Autistic and dysphasic children. I. Clinical characteristics. Pediatrics 1991;88: $1211-18$.

45 Mouridsen SE, Andersen LB, Sørensen SA, et al. Neurofibromatosis in infantile autism and other types of childhood psychoses. Acta Paedopsychiatr 1992;55:15-18. 